\title{
Personal Curation in a Museum
}

\author{
BEN RYDAL SHAPIRO, Georgia Institute of Technology, School of Interactive Computing, USA ${ }^{1}$ \\ ROGERS HALL, Vanderbilt University's Peabody College of Education, USA
}

\begin{abstract}
An established body of work in CSCW and related communities studies social and cooperative interaction in museums and cultural heritage sites. A separate and growing body of research in these same communities is developing ways to understand the design and use of social media from a curating perspective. A curating perspective focuses on how social media is designed and used by people to develop and manage their own digital archives. This paper uses a cultural heritage museum as the empirical basis and setting along with new information visualization methods we have developed to better integrate these bodies of work and introduce the concept of personal curation; a socio-technical practice in which people collect, edit, and share information using personal information devices and social media as they move through physical environments rich with meaning potential. In doing so this paper makes three contributions. First, it illustrates how to combine a spatial focus on people's movement and interaction through the physical environment with an analysis of social media use in order to gain a deeper understanding of practices such as personal curation. Second, it shows in greater detail how visitors to museums and cultural heritage sites use and link digital information with physical information to shape others' understandings of cultural heritage. Third, it suggests how museums and cultural heritage sites may leverage personal curation to support more expansive learning opportunities for visitors.
\end{abstract}

CCS Concepts: $\bullet$ Human-centered computing $\rightarrow$ Collaborative and social computing; Visualization; Empirical studies in collaborative and social computing; Visualization application domains

\section{KEYWORDS}

Computer-supported cooperative work; social media; museum studies; learning sciences; information visualization; personal curation; cultural heritage; interaction geography;

\section{ACM Reference format:}

Ben Rydal Shapiro and Rogers Hall. 2018. Personal Curation in a Museum. In Proceedings of the ACM on Human-Computer Interaction, Vol. 2, CSCW, Article 158 (November 2018). ACM, New York, NY. 22 pages. https://doi.org/10.1145/3274427

\section{INTRODUCTION}

An established body of work in CSCW and related communities studies social and cooperative interaction in museums and cultural heritage sites [12, 33, 55, 61, 65]. A separate and growing body of research in these same communities is developing ways to understand the design and use of social media from a curating perspective. In contrast to studying how social media is designed and used to perform identity and manage social relationships (i.e., a "networking perspective"), a curating perspective focuses on how social media is designed and used by people to develop and

\footnotetext{
${ }^{1}$ Ben Rydal Shapiro was previously a member of the Space, Learning \& Mobility Lab at Vanderbilt University's Peabody College of Education. Correspondence concerning this article should be addressed to ben@benrydal.com

Permission to make digital or hard copies of all or part of this work for personal or classroom use is granted without fee provided that copies are not made or distributed for profit or commercial advantage and that copies bear this notice and the full citation on the first page. Copyrights for components of this work owned by others than the author(s) must be honored. Abstracting with credit is permitted. To copy otherwise, or republish, to post on servers or to redistribute to lists, requires prior specific permission and/or a fee. Request permissions from Permissions@acm.org.

Copyright is held by the owner/author(s). Publication rights licensed to ACM.

2573-0142/2018/November - ART158 \$15.00 https://doi.org/10.1145/3274427
}

Proceedings of the ACM on Human-Computer Interaction, Vol. 2, No. CSCW, Article 158, Publication date: November 2018. 
manage their own digital archives [ 70 also see $34,41,43,67,71]$. In this paper, we integrate these separate bodies of work in order to better understand and potentially design for how people use personal information devices (e.g., smart phones, cameras) and social media as they move through physical environments rich with meaning potential. Likewise, we illustrate concepts and methods particularly relevant to the educational goals of museums and cultural heritage sites.

The setting and empirical basis of this paper is a three-year project to understand how visitors cultivate interests in and learn about the diverse historical and cultural heritage of American Roots and Country music as they visited a nationally renowned museum located in the mid-South region of the United States. Two primary questions guided our work. First, we wanted to understand how people's use of personal information devices and social media was organized over space and time as they moved across and talked together about exhibits and museum gallery spaces. Second, we wanted to study how visitors used personal information devices and social media to collect, edit, and share information from their visit, for example, to share examples of unfamiliar musical instruments with a friend, contribute to a growing historical account of their favorite musician's career, or prepare detailed, close-up samples of textiles from costumes that visitors plan to use as inspiration for their own professional goals.

To answer these questions, we collaborated with museum partners, participating visitor groups/families, and our university's institutional review board (IRB) to collect a purposive sample of complete museum visits across 22 visitor group cases (2-5 visitors per group) over a period of six weeks. Data from these 22 case studies came from three sources. First, we collected continuous, multi-perspective video and audio records (72 hrs total) of each visiting groups' movement, interaction, and social media use through small, unobtrusive cameras worn as necklaces for the duration of the visit with no researchers present (visits ranged from 30 min to 4 $\mathrm{hrs}$ ). These cameras notably allowed us very close access to how visitors manipulated smart phones, tablets, and cameras that they carried into the museum gallery spaces. Second, following each visit, we conducted 1-2 hr post-interviews with each visitor group. These interviews focused on how visitors used personal information devices and social media during their museum visit as well as in their everyday lives. The post-interviews often included walks back through the museum with researchers present, providing visitors with opportunities to explain points of interest and places where they used personal information devices and social media to collect, edit, and share content during their visit. Third, during post-interviews we also connected with visitors directly on "followable" social media platforms such as Facebook, Instagram, and Twitter (i.e., as a friend or a follower). We remained a friend or follower for 2 weeks after the visit to study the social life of digital content (e.g., photographs, posts, videos) that visitors shared during and after their visit on followable social media.

In this paper we analyze these data using a grounded theory approach $[11,28]$ and new information visualization methods we have developed to introduce the concept of personal curation; a socio-technical practice in which people collect, edit, and share information using personal information devices and social media as they move through physical environments. In doing so, we make three contributions. First, we illustrate how to combine a spatial focus on people's movement and interaction through the physical environment with an analysis of social media use in order to gain a deeper understanding of practices such as personal curation. Second, we extend existing research to show in greater detail how people use and link digital information with physical information to shape others' understandings of cultural heritage. Third, we suggest how museums and cultural heritage sites may use concepts and methods in this paper to support more expansive learning opportunities for visitors. 
We begin by discussing relevant work in CSCW and related communities and by introducing methods of interaction geography we have developed in prior work at this museum [56, 57] that, in this paper, we use as part of our approach to study personal curation. Subsequently, we describe our methods of analysis. We then report three levels of analysis, starting with a general picture and then moving progressively to a more fine-grained account of personal curation. First, we provide an overview of how visitors across the 22 cases in our study used personal information devices and social media during and after their visits. Second, we use methods of interaction geography to track in a finer-grained way the organization of four families/groups' use of personal information devices and social media across three different museum gallery spaces. Third, we conduct a detailed analysis of one visitor to characterize personal curation as a socio-technical practice. We conclude by discussing three primary contributions of this early work and by critically discussing limitations and next steps.

\section{RELEVANT WORK}

\subsection{Visitor Interaction in Museums \& Cultural Heritage Sites}

Our study is informed by and contributes to an established body of scholarship that studies social and cooperative interaction in museums and cultural heritage sites. This research uses audio and video-based methods such as conversation or interaction analysis [27,37] that are "sensitive to social interaction of a moment-to-moment grain size" [17] to illustrate the socially situated nature of visitors' activities [1, 12, 22, 62, 65]. This research produces detailed descriptions of visitors' conversation and interaction (e.g., transcripts of conversation). These descriptions have in turn supported museums and cultural heritage sites' efforts to move away from solely "inward-looking roles" as curated collections to more "outward-looking roles" as places that engage visitors in interactions about the meaning of archival material often in relation to broader societal themes (e.g., climate change) [53]. Likewise, these descriptions have also contributed to a shift in studies of visitor behavior from understanding exhibits and archival content as a fixed curriculum that visitors succeed or fail at understanding towards a view of visitor engagement and interaction as an "enacted curriculum" [14]. Moreover, this body of research as a whole informs the design, development, and assessment of interactive technology in museums and cultural heritage sites (e.g., to customize visits [25, 26], develop and study navigation systems [4, $30]$, support visitors' access to information [6, 62], and evaluate visitor engagement and learning [51]).

Two acknowledged limitations in this body of research serve as important starting points for this paper. First, this research has not developed methods to link fine grained analyses of visitors' conversation and interaction at single museum exhibits with their spatial interaction and movement across gallery spaces, for example, to support studying and designing for collaborative interaction across exhibits and gallery spaces [62]. Put differently, this body of research remains separate from a related body of work (not reviewed here) that seeks to study and track visitors' activity (e.g., typically movement) across museums and cultural heritage sites at larger scales [see $5,15,39,60,63,69]$. Second, the types of visitor practices that are occurring within museums and cultural heritage sites continue to expand rapidly: As a result, there is a need "to extend CSCW's nuanced understanding of visitors to include practices of study, work, apprenticeship, voluntary participation, etc., and not simply leisure or informal learning” [13]. More specifically, we suggest that there is a need to integrate previous research about visitors' "collecting practices" or how 
visitors collect and keep content as opposed to consuming content [47] with new research that seeks to understand visitors' use of personal information devices and social media during and after their visits to museums and cultural heritage sites.

\subsection{Towards a Curating Perspective}

A mostly separate body of research in the CSCW and related communities is developing ways to study the design and use of social media from a curating perspective. Three related lines of inquiry within this body of research are advancing a curating perspective. One studies how people's performance of identity and management of social relationships on social media is mediated by the ways in which social media sites perform curatorial roles $[8,10,16,18,19,20$, 45]. Hogan's "exhibitional approach" to characterizing social media sites epitomizes this work [34]. An exhibitional approach emphasizes that social media sites are curators through their algorithmic and visual design. In particular, this approach explicates how the logic by which social media sites filter, order, store, and display digital information (e.g., through Facebook's news feed $[21,49])$ mediates how people are able to use social media to perform identity and manage social relationships.

A second line of inquiry shows how users play an equally important curatorial role $[29,64$, 70, 71]. For example, Zhao and Lindley's notion of "curation through use" suggests that people use social media to select, organize, annotate, and tell stories with and about information to construct their own personally meaningful digital archives [70]. Likewise, Zhao and Lindley illustrate how social media is part of a broader set of ways in which people archive digital content from their everyday lives. This line of work more specifically considers how people (often unintentionally) use social media to curate content (e.g., collect, organize, archive, display) over longer periods of time [42, 44].

A third line of inquiry explores how social media requires new definitions of curation [35, 38, 43, 46]. Sophia Liu's concept of socially distributed curation is an early and influential example and begins from the premise that people experience curatorial overload (i.e., people are unable to consume the vast amounts of digital information that exist in online settings and on social media) [43]. As a result, Liu suggests, people will increasingly engage with separate but integrative curatorial roles on social media/in online settings. As Liu describes, some of these roles include the archivist, who builds collections of digital artifacts, the editor, who verifies the authenticity of digital artifacts and collections, the exhibitor, who displays and exhibits narratives from artifacts and collections, and the docent, who teaches visitors about collections and artifacts [43].

The application of the curating perspective (and other types of digitization initiatives) in settings such as museums and cultural heritage sites is limited in an important way that serves as a starting point for our paper. Namely, existing definitions of curation rarely consider how dimensions of curation (e.g., information gathering, filtering, archiving, displaying, or storytelling) are influenced by in the moment conversation, interaction, and movement through physical spaces as well as the physical design/layout of these spaces [3, 24, 48]. In other words, for museums and cultural heritage sites in particular, the acknowledged potential of the curating perspective is limited by the lack of research describing how visitors' in the moment interactions with personal information devices and social media during visits bridge archival collections with the everyday lives of visitors [27]. Such research necessitates studying how visitors' in the moment interactions during their visit produce opportunities for visitors to create their own digital collections following their visit. Similarly, such work entails studying how visitors' social 
media practices and ecologies $[66,68]$ shape their interactions (e.g., their movement trajectories) during their visit.

\subsection{Interaction Geography}

The two previous sections raise important and unanswered questions about what methods can link micro-analyses of visitors' interaction and use of personal information devices at exhibits with a) analyses of visitors' interaction and use of personal information devices across gallery spaces and b) larger scale analyses of visitors' use of social media. Figure 1 is a snapshot that begins to illustrate interaction geography, an approach we have developed in previous work (in this museum setting) to describe, represent, and interpret people's interaction as they move within and across physical environments [56, 57]. Interaction geography integrates and extends interaction analysis [37] and time geography [31] and employs methods we have and continue to develop including a) Mondrian Transcription, a method to transcribe and map people's movement and conversation over space and time and b) the Interaction Geography Slicer (IGS), a dynamic visualization tool that supports new forms of interaction and multi-modal analysis.

We next explain how to read Figure 1 in order to support analyses that use these methods presented later in this paper. The figure maps the movement of a six-year-old boy, Blake (blue path), and his sister's fiancé, Adhir (orange path), as they visit a museum gallery together. Blake and Adhir are two members of a five-member family that we call "The Bluegrass Family" who participated in this study. Also included in the figure is a rendering showing the gallery space from a point marked on the floor plan.

The left of the figure or "floor plan view" shows Adhir and Blake's movement over a floor plan of the gallery space (i.e., looking down on the space). This view shows where Blake and Adhir go within the gallery space. The right, or "space-time view" [31] extends Blake and Adhir's movement on the floor plan horizontally over time. This view shows how they interact with exhibits and one another over time.

For example, the space-time view shows that after entering the gallery space (top left of the floor plan view and beginning of the space-time view), Adhir and Blake walk together toward an exhibit about Hank Williams (marked on the floor plan). Subsequently, Adhir stands for almost 5 minutes at the Hank Williams exhibit, as indicated by his horizontal orange path in the spacetime view that extends from approximately minutes $0-5$ and corresponds to the vertical position of the Hank Williams exhibit in the floor plan view. In the meantime, while Adhir is standing, Blake is moving quickly (apparently running) back and forth across the gallery space (i.e., across the semi-circle of exhibits on the floor plan) in multiple attempts to draw Adhir away from the Hank Williams exhibit. After four failed attempts, Blake finally succeeds in leading Adhir on what we describe as a tour of other exhibits in the gallery, indicated by their intertwined paths from approximately minutes 5-6. The change in line pattern in Blake's path distinguishes between three different horizontal areas of space on the floor plan providing some description of horizontal movement on the floor plan in the space-time view. This technique has limitations but becomes more relevant when more people are shown.

Having briefly described how to read these displays, we now turn to describing the methods that were used in the present study. 


$$
\text { Adhir }^{25} \text { Blake }^{6 \text { years old }}
$$

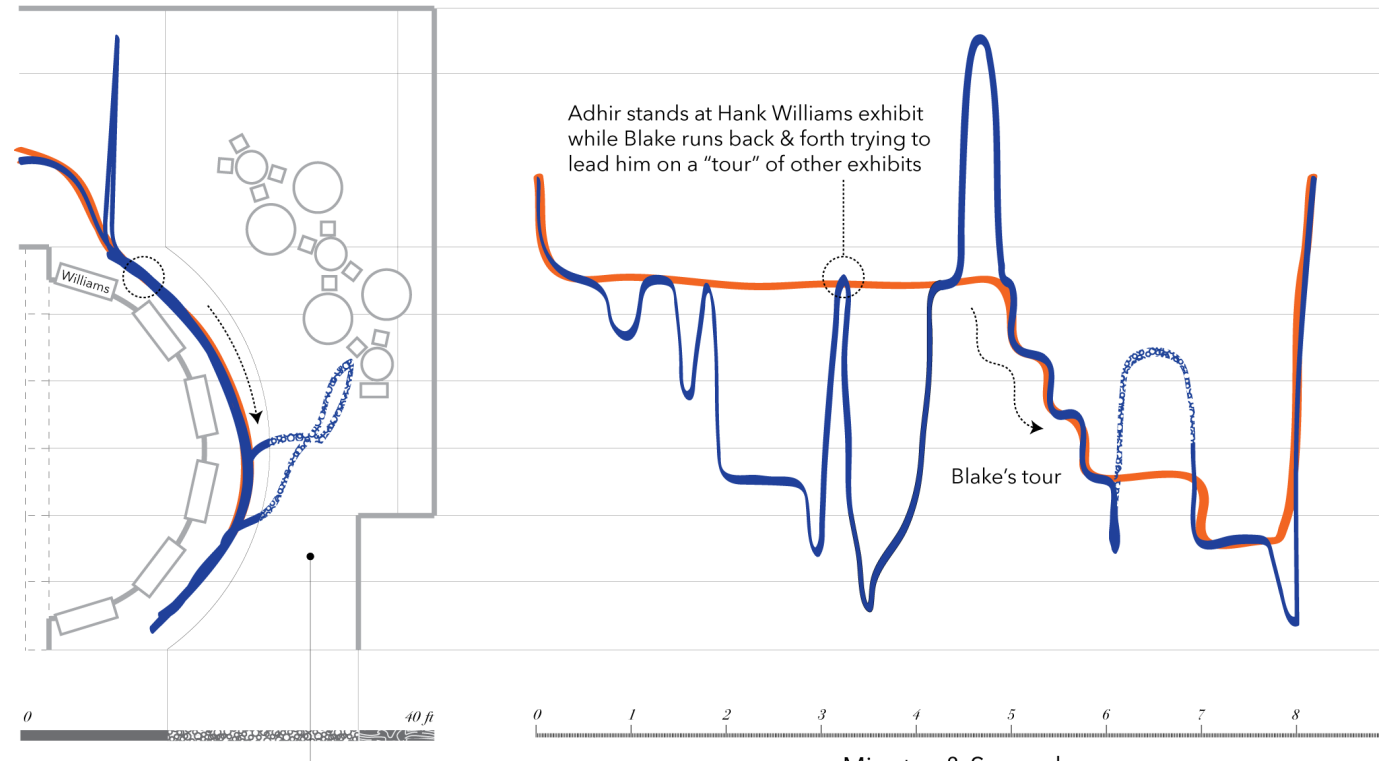

Minutes \& Seconds

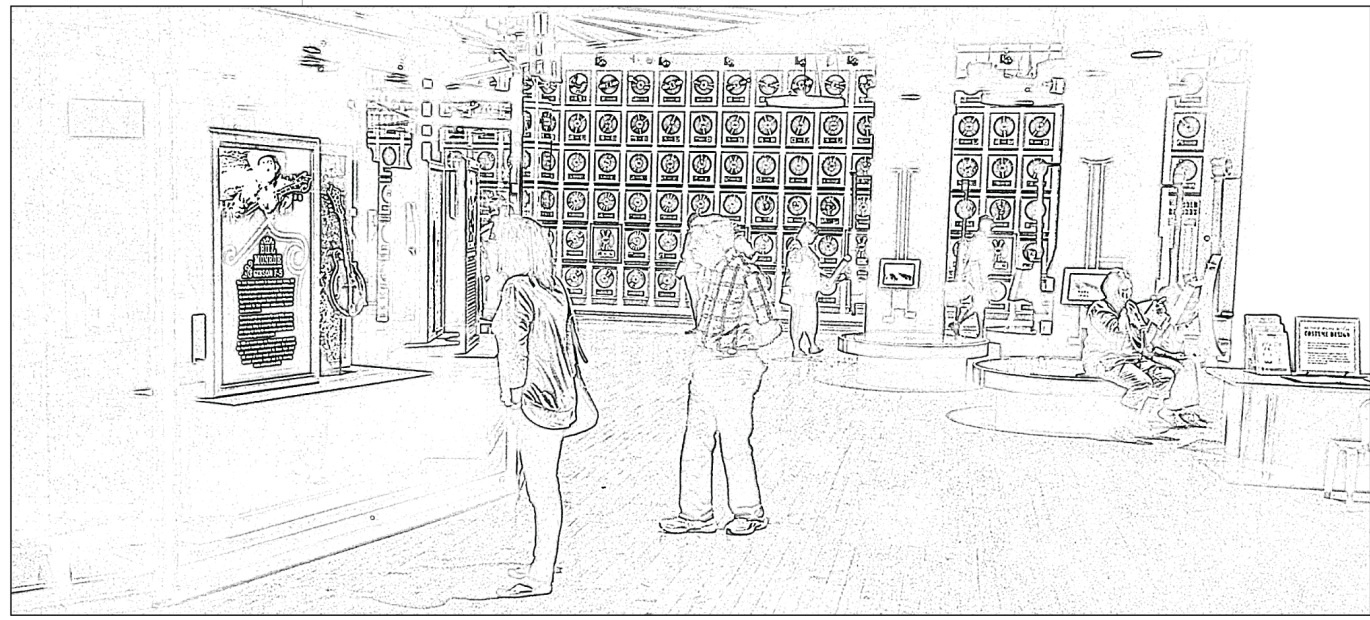

Fig. 1. Adhir and Blake's movement in a museum gallery space is shown over space and space-time. Copyright (c) Ben Rydal Shapiro. Reprinted by permission

\section{METHODS}

Our initial fieldwork and data collection procedures began with participant observation in the ethnographic tradition. We observed typical visitor activity within exhibit spaces, but we also observed how visitors explored the nearby city and engaged with the museum virtually before and after their visit (e.g., by joining visiting families as they toured nearby sites). Such efforts reflected our efforts to understand this museum as an institution and a networked field site [8, 18]. 
Following this initial fieldwork, we collected and analyzed the multiple forms of data described at the beginning of this paper. To analyze these data, we followed a grounded theory approach [11, 28]. We constantly and iteratively compared, tested, and refined emergent analytical categories to create stable conceptual categories. We did so through three primary lines of analysis.

First, we synchronized and content-logged all multi-perspective audio and video from museum visits and post-interviews across the 22 visitor group cases in our study. In particular, we identified and categorized the use of personal information devices and social media (e.g., when, where, how long, types of uses, types of social media platforms) during museum visits and triangulated these categories with visitors' reflections on their use of their devices and social media during post-interviews.

Second, we used methods of interaction geography to synchronize visitor groups' use of their devices and social media to their movement and conversation across exhibits and gallery spaces. We used methods of interaction and conversation analysis [32, 37] to conduct microanalyses of visitors' use of personal information devices and social media during their visit as well as online conversations on social media around shared, digital artifacts following their visit. These efforts align with recent calls in the CSCW community to use methods such as conversation analysis in studies of social media [50].

Third, we logged visitors' social media activity related to their museum visit on followable social media platforms twice a day for a period of two weeks after their visit. This entailed logging information such as when digital artifacts were shared during and after museum visits, how many likes and comments each artifact generated, and analyzing online conversations that developed around artifacts. We also triangulated this analysis with visitors' reflections during their post-interviews on their typical social media practices and ecologies (i.e., use of different social media platforms for particular purposes) and their use or intended/future use of content gathered from their museum visit. There are limitations to this third line of analysis. For example, although we connected with most visitors during the post-interview who shared or intended to share content on followable social media platforms, some visitors may not have disclosed all social media platforms they use. Likewise, we chose to follow visitors as friends or followers for a period of only 2 weeks. As a result, visitors could have shared material after that time; if so, these occurrences were not encompassed by our analysis.

\section{ANALYSIS \& FINDINGS}

\subsection{Overview of Visitor Activity}

Table 1 provides one way to see the extent and variation in how the 22 visitor groups in our study used personal information devices and social media to collect, edit, and share content during and after their museum visit.

For example, the table shows that over half of these visitor groups including both teens and adults collected photographs/other forms of media (e.g., by taking photos/recording videos), edited these media (e.g., by creating collages/albums), and shared followable social media posts from their visit. Likewise, the table also highlights phenomena such as that the varying levels of likes/comments these posts received, and how in many groups, a single individual or curator appears responsible for sharing content. 
Table 1. Overview of 22 visitor groups and followed social media posts. Each row in the table corresponds to 1 of 22 visitor groups. For example, visitor group 1 from Pittsburgh, PA completed their visit together in 1 hour and 40 minutes. Of the 3 people in the group, 2 shared single posts to the followed social media platforms of Instagram and Facebook. Together these posts received 16 likes and comments.

\begin{tabular}{|c|c|c|c|c|c|c|}
\hline & $\begin{array}{l}\text { Hometown } \\
\text { * family group }\end{array}$ & $\begin{array}{l}\text { Visit Length } \\
\text { (hr: } \min \text { ) }\end{array}$ & $\begin{array}{l}\text { People } \\
{ }^{*} \text { musician }\end{array}$ & $\begin{array}{l}\text { People w/ Post } \\
\text { 40-60yrs old } \\
20-30 \text { yrs old } \\
\text { 10-20yrs old }\end{array}$ & $\begin{array}{l}\text { Type of Post } \\
\text { ह If single post/platform } \\
x^{\mathrm{x}} \text { \# of photographs } \\
\mathbf{\square} \text { album/collage } \\
\{\} \quad \text { multiple visitors }\end{array}$ & Likes \& Comments \\
\hline 1 & Pittsburgh, PA & $1: 40$ & $\bullet \bullet \bullet$ & - & $\{\vec{\sigma}\}\{\mathbf{f}\}$ & 16 \\
\hline 2 & Fresno, CA & 1:09 & $\bullet$ & $\bullet$ & 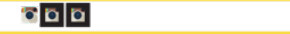 & 101 \\
\hline 3 & Staten Island, NY & $\begin{array}{r}47 \\
1: 04 \\
1: 08\end{array}$ & $\begin{array}{l}0^{*} \\
0^{*} \\
0^{*}\end{array}$ & & & \\
\hline 4 & South Korea & $\begin{array}{l}52 \\
56\end{array}$ & 0 & - & $\mathbf{f}^{10}$ & 29 \\
\hline 5 & $\mathrm{TX}^{*}$ & $3: 43$ & $\bullet \bullet \bullet \bullet$ & $\bullet$ & $\boldsymbol{f}^{67}$ & 7 \\
\hline 6 & Nova Scotia \& MI & $1: 37$ & $0^{*} \mathbf{Q}^{*}$ & - & $\overline{\boldsymbol{\sigma} \boldsymbol{\sigma} \boldsymbol{y}}$ & 169 \\
\hline 7 & Cordele, GA & $1: 34$ & $\bullet \bullet \bullet$ & & & \\
\hline 8 & Holland, MI & 1:09 & $\bullet \bullet \bullet$ & - & $\mathbf{f f}^{25} \mathbf{f f}^{30}$ & 5 \\
\hline 9 & Staten Island, NY & 44 & $\bullet$ & 00 & $\{\vec{\sigma}\}\{\boldsymbol{\sigma}\}$ & 58 \\
\hline 10 & lowa City, IA * & $1: 46$ & $\bullet \bullet \bullet$ & & & \\
\hline 11 & St. Mary's, PA* & $1: 09$ & $\bullet \bullet \bullet \bullet$ & $\bullet$ & If & 4 \\
\hline 12 & Owings, MD * & $1: 16$ & $\bullet \bullet \bullet \bullet$ & $\bullet \bullet$ & $\{\sigma \sigma \sigma \sigma \sigma \sigma\}\left\{\sigma \sigma f^{3}\right\}\left\{f f f f^{2}\right\}$ & 103 \\
\hline 13 & London, UK* & $1: 07$ & ๑०० & & & \\
\hline 14 & Atlanta, GA & $\begin{array}{l}1: 39 \\
2: 12\end{array}$ & ? & & & \\
\hline 15 & GA \& England & 1:05 & $\bullet \bullet \bullet \bullet$ & & & \\
\hline 16 & Hazlet, NJ * & $1: 25$ & 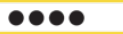 & & & \\
\hline 17 & Washington, D.C. & 58 & $\bullet$ & $\bullet$ & $\{[f\}\{f\}$ & 58 \\
\hline 18 & Big Sur, CA * & 49 & ๑*ดัดัดัด & $\bullet \bullet$ & 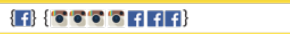 & 55 \\
\hline 19 & Sunrise, FL * & $1: 56$ & $\bullet \bullet \bullet$ & & & \\
\hline 20 & Milwaukee, WI * & 1:08 & 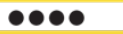 & 0 & $\mathbf{f}^{12}$ & 5 \\
\hline 21 & Port Charlotte, FL * & 1:04 & $\bullet \bullet \bullet \bullet$ & $\cdot 0$ & $\left\{\cdot \boldsymbol{f}^{12}\right\}\left\{\boldsymbol{f}^{15}\right\}$ & 98 \\
\hline 22 & Chicago, IL* & $\begin{array}{r}38 \\
1: 33\end{array}$ & •* & 0 & $\left\{\mathbf{I f}^{9}\right\}$ & 8 \\
\hline Ra & ange: & 38 to $3: 43$ & 2 to 5 & 1 to 3 & 0 to 13 Online Postings & 4 to 169 \\
\hline
\end{tabular}

Our analysis of audio and video records and post-interviews from each groups' visit provides more detailed information to further interpret and extend the meaning of Table 1 . All visitor groups collected photographs of exhibits and artifacts, ranging from 3-245 photographs per group. Some visitors also collected videos, but this was not common. To collect information from their visit, visitors used a variety of personal information devices, including smart phones, iPads, cameras, and, in one instance, a polaroid camera that printed pictures during their visit. For example, one visitor in visitor group 14 used her smart phone and camera (often simultaneously) to take nearly 200 photographs during her $1 \mathrm{hr}$ and 39 minute visit. As Table 1 shows, these photographs were not shared on followable social media. Not followable social media typically included Snapchat, various group text applications (e.g., WhatsApp), and note-taking applications (e.g., Endnote).

Visitors edited and shared collected digital content at a short-term timescale (i.e., the same day often during their visit) for two primary purposes. First, visitors did so to perform identity and managed social relationships. For example, visitors edited (e.g., by cropping photographs or 
annotating media with captions/messages) and shared (i.e., by posting to followable and not followable social media) collected content to highlight their efforts to pose with museum exhibits [51]; to involve others not present in their museum experience; to geolocate or indicate and even show off that they were visiting this particular museum; and to voice their personal opinions about the museum. Second, visitors edited and shared collected digital content at a short-term timescale to interpret information in the physical museum environment. For example, visitors conducted web searches to translate museum signs/information and answer questions about museum content, composed and received messages from others to help locate artifacts in the museum, and occasionally used music streaming services to locate/listen to music while visiting exhibits. In our view, these uses of personal information devices and social media are consistent with existing research in the curating perspective that describes activities like these as "...the curation of representations of physical place and mobility to perform identity online" [54].

Visitors also edited and shared collected digital content at a larger timescale (i.e., days or weeks after their visit) for two different reasons. First, visitors edited collected digital artifacts from their visit (e.g., to create a collage or album) that, as they described in their post-interviews, served to memorialize their museum visit/experience. These artifacts or micro-collections were intended to archive visits and experiences in ways consistent with descriptions from the curating perspective. But, in addition, visitors described how they shared edited and collected digital content from their museum visit to develop their own personal digital archives in order to teach/educate others or to pursue their own interest-driven learning [36]. For example, in their post-interview, Mika and Olivia, who were middle school teachers (visitor group 2 in Table 1), described their intentions to display and discuss digital content collected during their visit on their online teaching channels in order to advance their classroom teaching. In particular, Mika and Olivia described how they collected many photographs of notebooks with handwritten song lyrics by famous musicians displayed throughout the museum. These notebooks provided cues about how musicians revised their songs (e.g., by crossing out lyrics). As Mika described, "The revisions....and I could see using something like this in my classroom, where getting the kids to understand that oftentimes when they write something they think, I already wrote it it's good, it's good enough... NO, even people who... this is what they do; they revise something until it is good enough."

Another visitor, Helen, collected nearly 60 photographs across her visit. These photographs focused on (i.e., zoomed in on) the construction details of many different types of instruments (e.g., the design of frets and fretboards on guitars). She explained she did so because she builds acoustic guitars as a hobby and that this museum was a rare place for her to collect information that illustrated how older guitars were built. She additionally reported that she intended to further edit these photographs by organizing them into mini-collections for her own reference/personal learning and to share and discuss these collections with her Korean crafting group upon her return to her home in South Korea.

A different visitor, Marion (of visitor group 14) also collected many detailed photographs of the characteristics of artifacts throughout her visit. Unlike Helen however, Marion's photographs focused on the stitching patterns of clothing because, as she explained in her post-interview, the clothing featured in this museum was very rare and revealed historical stitching patterns she had not previously seen. Moreover, she described how she intended to share some of these photographs on a section of her personal business website that teaches others about the history 
of sewing. At the time of our study, Marion was building this website to begin selling clothing as a hobby and potentially a full-time business.

In summary, in this section we provided an overview of how visitors in our study used personal information devices and social media extensively to collect, edit, and share information in a variety of ways both to perform identity and to develop their own personal digital archives, often for the purposes of teaching or learning.

\subsection{Using Interaction Geography to Analyze Visitor Activity}

Our previous analysis further highlights the need for new methods to more specifically characterize how people collect, edit, and share information with their personal information devices and social media as they move across exhibits and gallery spaces. Figures 2 and 3 are screenshots from the Interaction Geography Slicer (IGS). They use conventions of interaction geography described previously to integrate the movement of four visitor families/groups across three different gallery spaces with their use of personal information devices and/or social media. Figure 2 shows continuous movement for each family/group whereas Figure 3 shows traces of movement where visitors are using personal information devices and/or social media to collect, edit, and/or share content (in ways described previously) from the museum. Columns in each figure distinguish each visitor group/family, while rows indicate different gallery spaces. All displayed information across these figures is set to the same scales. Since the "Taylor Swift Family" (they expressed intense interest in Taylor Swift) did not visit the Rotunda Gallery, we have combined all visitor groups' movement or use of personal information devices and social media on a floor plan drawing of the entire museum.

These figures extend our previous analysis in four ways. First, they are a new way to see and study the extent and variation at individual and group levels of visitors' use of personal information devices and social media to collect, edit, and share information across exhibits and gallery spaces. For example, in Figure 3 shorter lines or "points" of movement in the space-time view for each family/group in each gallery space are typically moments where visitors collect information (e.g., a single photograph). Longer lines or "path segments" are typically sequences where visitors also edit this information (e.g., apply a filter to a photograph, compose a message or caption), and/or share this information by posting it to social media. For example, the Business Partners ( $3^{\text {rd }}$ column and visitor group 6 in Table 1) and especially Andy (orange path) collect many single photographs in the Folk Roots Gallery, as indicated by the many points of movement in the space-time view ( $3^{\text {rd }}$ column, $1^{\text {st }}$ row). However, in the Bluegrass and Rotunda Galleries the many longer lines of movement shown in the space-time view indicate how Andy in particular is using personal information devices and/or social media for much more extended periods of time. During many of these sequences Andy is editing photographs of artifacts in this gallery space that he has collected by annotating them with messages and subsequently sharing these edited photographs with up to twenty-four followers at once on social media platforms such as Snapchat.

Second, these figures illustrate how the use of personal information devices and social media occurs alongside more commonly studied communication practices, such as movement and conversation (see [56] for figures that show conversation). In other words, interaction geography provides one way to study how the use of personal information devices and social media is organized in relation to how people interact with one another as they move through physical environments. 


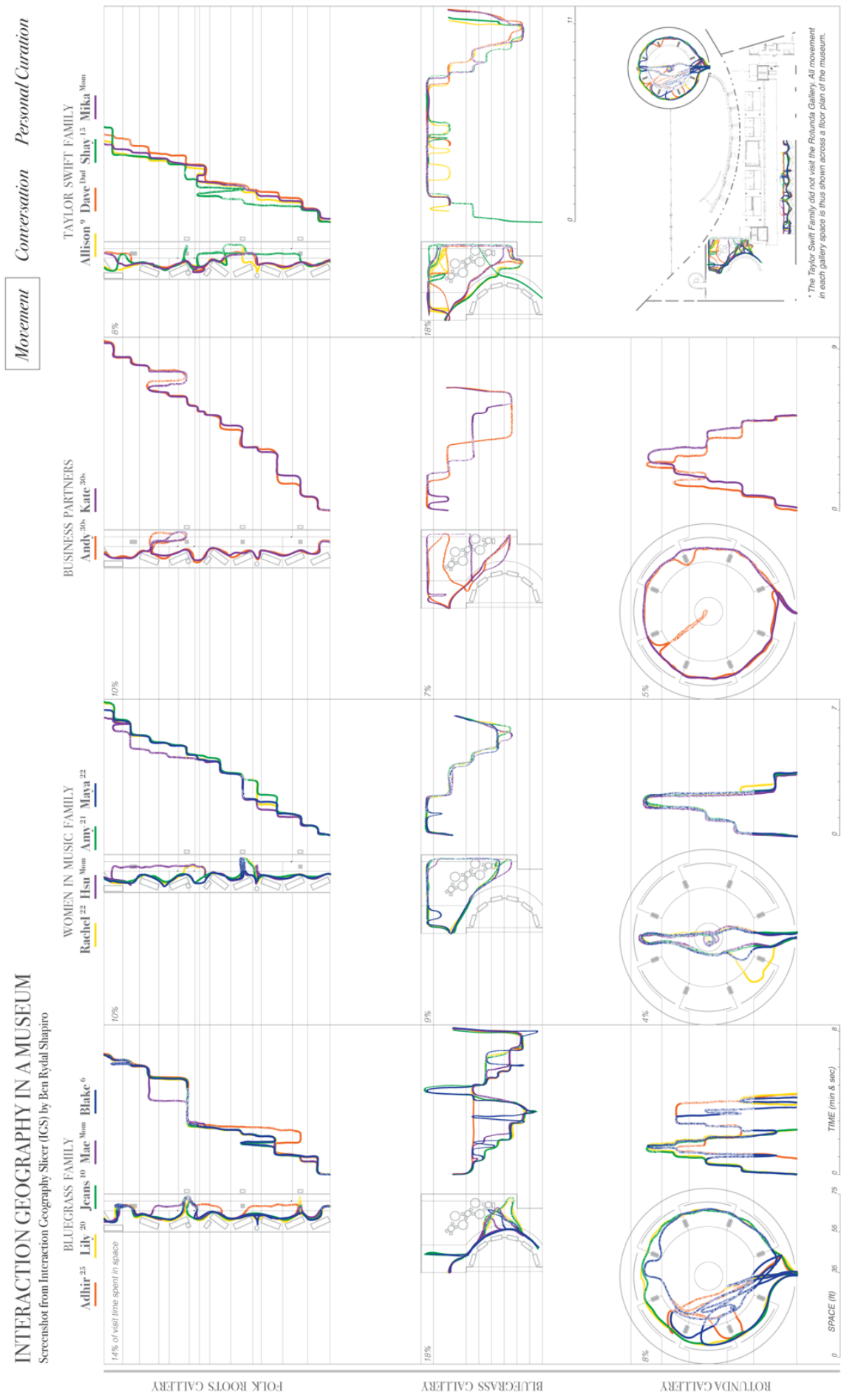

Fig. 2. IGS screenshot of visitor movement. @ Ben Rydal Shapiro. Reprinted by permission 


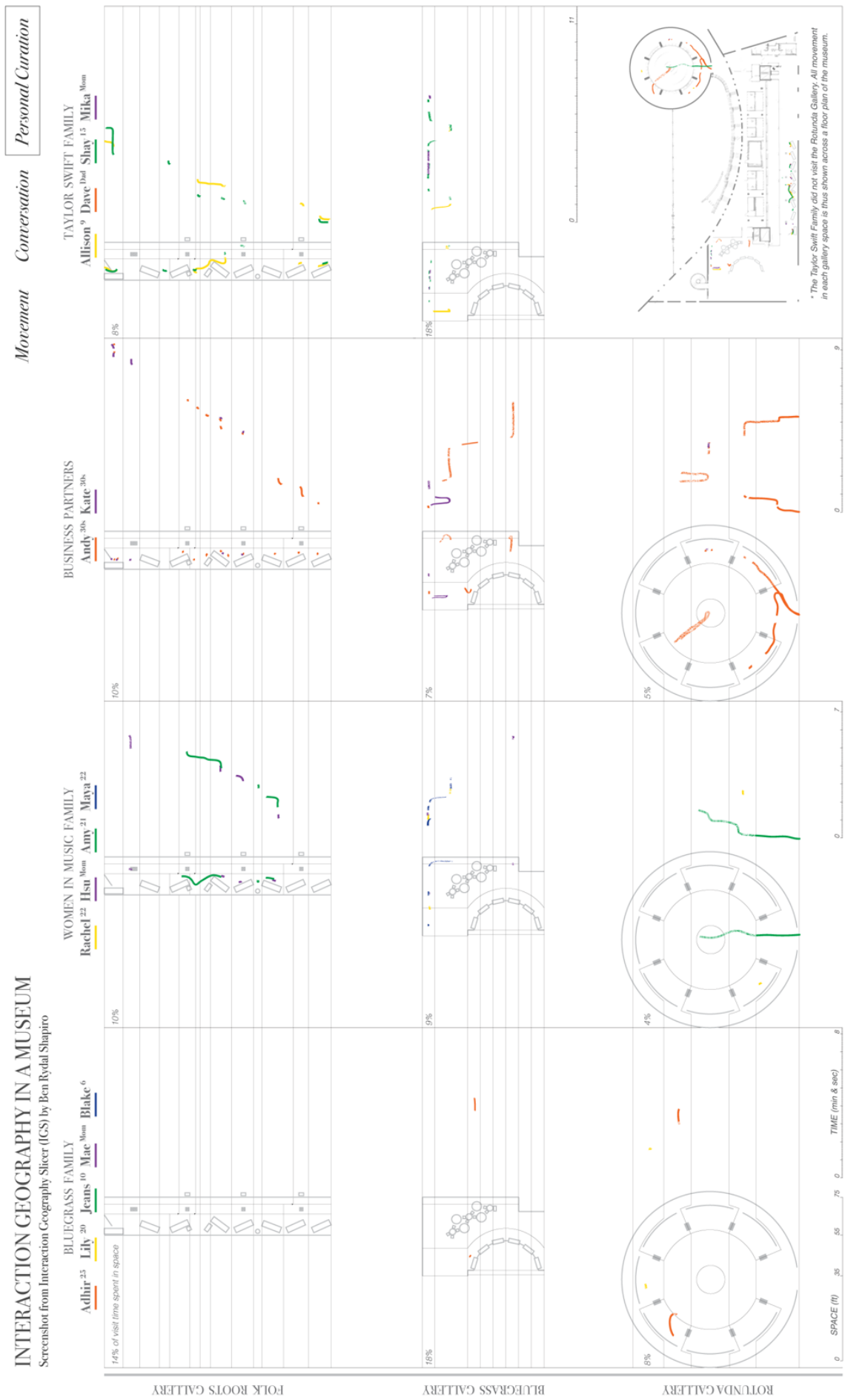

Fig. 3. IGS screenshot of visitor device/social media use. ( ) Ben Rydal Shapiro. Reprinted by permission 
Moreover, although these images are static, they are produced by highly dynamic tools (i.e., the IGS) that allow for more dynamic ways to study different types of communication practices simultaneously across scales. For example, one can use the IGS to select and rescale sequences of movement, conversation, and/or social media use over space and time, visualize and read conversation turns from each visitor at or across exhibits, and watch video of visitors' interaction and use of personal information devices and social media from the perspective of each visitor that was gathered as part of this research.

Third, the figures begin to highlight how interaction geography provides a means to understand the spatial organization of how people use personal information devices and social media to collect, edit, and share information as they move through the physical environment. For example, Points (as described above) are places and moments where people primarily collect digital content by taking photographs whereas Path Segments are places in the physical environment and sequences of interaction along which people edit and share collected digital content often while conversing with others not physically present while Regions refer to hot spots where visitors repeatedly use personal information devices and social media to collect, edit, and/or share content, in this study, around particular exhibits or regions of gallery spaces. The ability to describe the spatial organization of visitors' use of personal information devices and social media in this manner provides new ways to study how visitors' social media practices and ecologies shape their interactions (e.g., their movement trajectories) during their visit.

Fourth, for those who are familiar with these gallery spaces (e.g., museum curators, exhibit designers), the figure also highlights how these points, path segments, and regions provide insights about visitors' alignments to exhibit content across gallery spaces. For example, both figures show that much of the Women in Music Family's movement and use of personal information devices and social media focuses on museum content that features female artists. As described by this family in their post-interview, their visit was heavily influenced by the portrayal of female artists in this museum. Consistent with this statement, Figures 2 and 3 show the family likely uses their movement and social media to interact with exhibits and gallery spaces featuring female artists. Put differently, interaction geography provides one way to see how individuals/families can experience a personally edited version of a physical environment [40].

\subsection{Personal Curation}

Together, our previous analyses provide different ways to see the products and dimensions of personal curation (collecting, editing, sharing) that arise as a result of people's interaction and movement through physical environments rich with meaning potential. However, our analysis has not yet fully described personal curation as a socio-technical practice where people collect, edit, and share information through social media to contribute and manage their own digital archives.

To illustrate personal curation, we focus our analysis on Andy (one member of the Business Partners) whom Figure 3 indicates uses personal information devices and social media extensively across his visit. Andy, who is 31 years old, owns a small business that sells drum and percussion equipment. Music and drums have been Andy's lifelong passion. During our study, he visited this museum with a business partner, Cindy (33 years old). As Table 1 shows, Andy and Cindy (visitor group 6) completed their visit together in $1 \mathrm{hr}$ and $37 \mathrm{~min}$. During their visit, Andy took 165 photographs and, as shown in Table 1, after his visit, shared 5 of these photographs 
across Instagram, Twitter, and Facebook. These online posts together accumulated 169 likes and comments. On six other occasions during the visit, Andy also collected, edited, and shared photographs through texts and Snapchats with up to twenty-four people at once.

4.3.1 Collecting Information. Figure 4 is a transcript of Andy and Cindy's interaction with one another at a museum exhibit that features a drum kit. The transcript conveys how Andy approaches this exhibit, takes 2 photographs (this data comes from the video camera worn by Andy), and subsequently, draws Cindy (who is standing at a nearby exhibit) to join him (line 1 of the transcript) at this exhibit for a conversation that lasts almost 2 minutes.

Andy's first photograph captures the entire drum kit in the exhibit, while his second focuses on one part of the drum kit, the cymbal. The transcript also shows that Andy and Cindy's conversation (beginning at line 6) focuses primarily on who made the cymbal on the drum kit. In this case, who means not what individual, but which cymbal company, such as Wuhan or Zildjian (cymbal companies whose equipment Andy sells). Their conversation shows that they are unable to determine who made this cymbal, either from their observations and prior knowledge of the drum kit/percussion equipment or through signs provided by the museum, which provide no information about the origins of this cymbal. The conversation ends with Andy saying he will have to put the photo up on Instagram to see if anybody can "guess what it is" (line 23).

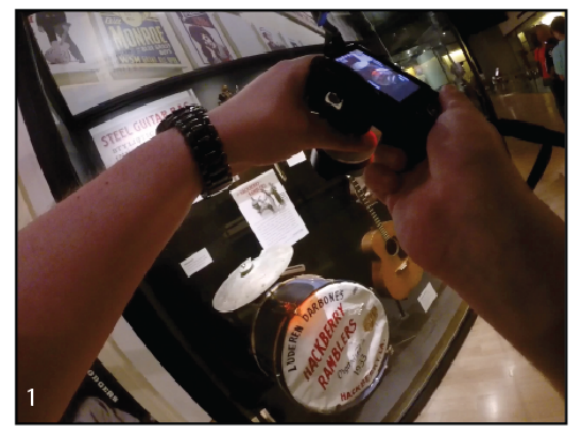

\section{Andy: ((captures photographs 1 and 2))}

1 A: this..this china cymbal ((points to cymbal)) is is

2 Cindy: WOW!

3 A: it's like so ancient

4 C: oh my goodness!

5 A: it's kind..kind of like the wu..look like the wuhan ones you..

6 C: I'd be curious to know who made that!

7 A:Idon't know

8 C: like what what was a similar around in the 20 s and 30s?

9 A: ((crouching)) it's nothing..I know its nothing ((stands up)) not no zildjian or nothing like that

10 C: ((points)) look at all the..NAILS in it

11 A: yea those are the rivets

12 C: so they put rivets in them back then to?

$13 \mathrm{~A}$ : I guess

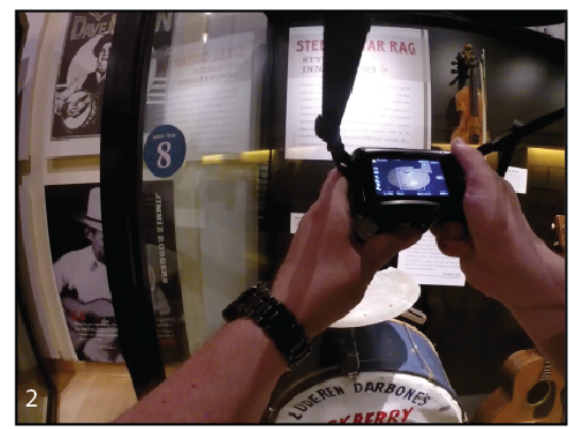

14 C: look at the ((points)) bass drum skin there

15 A: its uh.. it looks ((crouches)) I wonder is it like a cow skin?

$16 \mathrm{C}$ : what is it?

$17 \mathrm{~A}$ : is it like a cow skin like you know ((gestures cow skin on drum))

18 C: yea its like um animal skin right?

19 A:yea

20 C: like calf skin but that's the

21 C: that's cool

22 A: (stands up) I wonder who made the kit (laughs)

23 A: I'll have to put this up like on instagram see if..anybody can guess what it is

24 C: laughs

25 C: yea that would be a good spot for it to

26 A:yea

Fig. 4. Transcript of Andy and Cindy's engagement at a museum exhibit.

This analysis provides a detailed example of how visitors collect information from the physical environment through their movement, interaction, and use of personal information 
devices in ways that also begin to elaborate and personalize the meaning of content to align with their own interests and cultural identities.

4.3.2 Editing \& Sharing Information. Figure 5 is a post that Andy shared on his professional Instagram page (i.e., an Instagram account he uses to support his business) four days after his visit. Information on Andy's Instagram page is publicly available without being a friend or follower, which is an additional reason we have used his experiences as a case in our analysis. Nevertheless, we have removed all identifying information to preserve Andy's and others' anonymity. The figure shows the photograph of the cymbal that Andy collected during his visit, accompanied by a caption titled, "Anyone know who makes this Cymbal? Was display at the [name of museum]."

The title illustrates how Andy has edited and repurposed the photograph and overarching question from his conversation with Cindy during their museum visit in a post to his Instagram followers. Within two days after the image was posted on Instagram, it received 85 likes along with 6 comments from Andy's followers who provided different suggestions about the company that made this cymbal. The figure shows some of these comments, as well as Andy's responses to them, which at one point, even attempt to solicit interaction from Zildjian (i.e., by tagging the company).

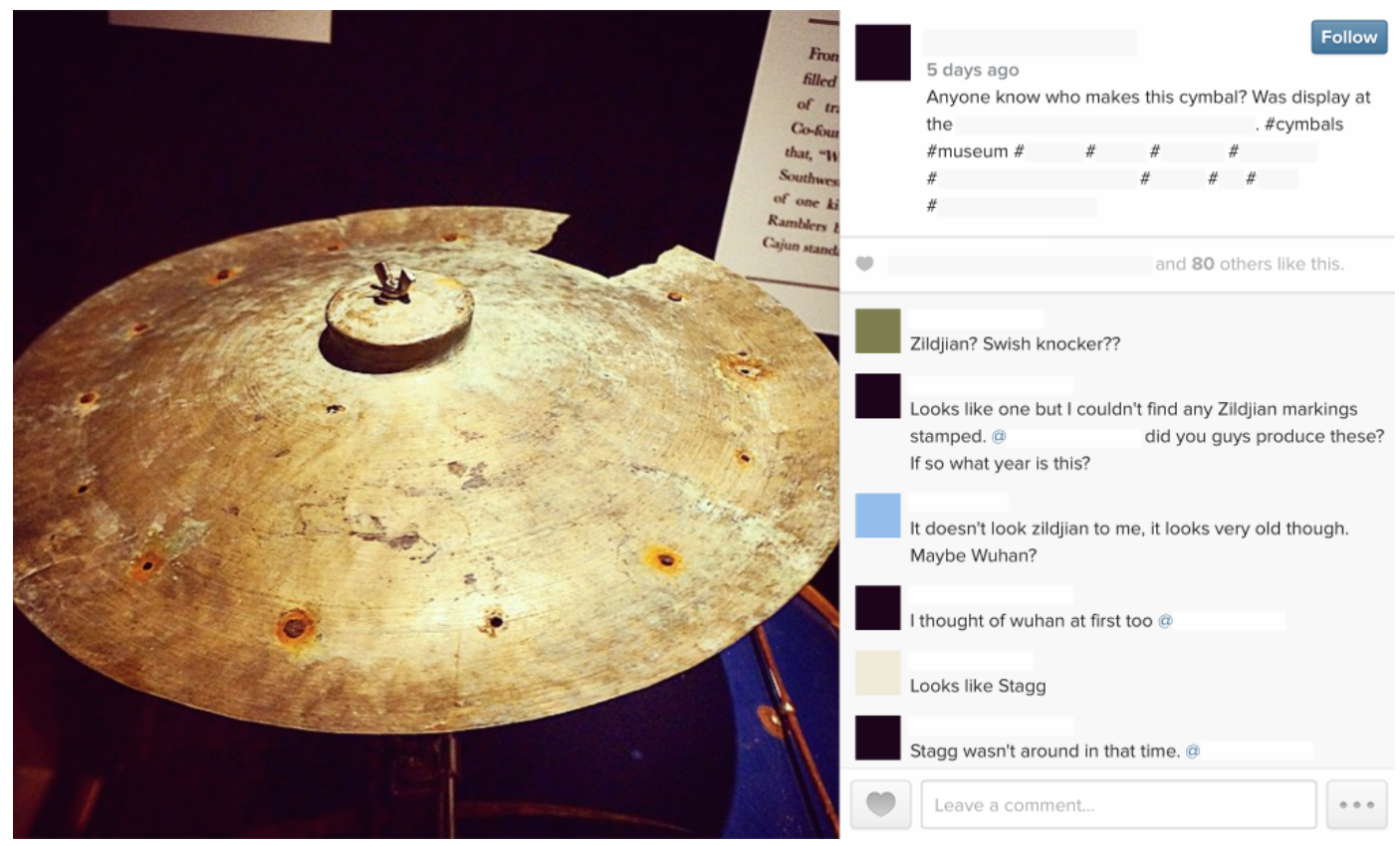

Fig. 5. An edited and shared digital artifact from Andy.

Altogether, this post illustrates how Andy has edited information that draws from content and his interaction with Cindy during their museum visit and shared this information on his professional Instagram page. 
4.3.3 Developing Personal Digital Archives. Figure 6 shows Andy's professional Instagram page. The figure depicts only a few of the 247 photographs on his Instagram page shortly after his visit to this museum. These photographs primarily display cymbals and other percussion equipment. One of the many photographs in the figure is the post analyzed previously. In his post-interview, Andy described that he owned his professional Instagram page for a year and a half at the time of his visit. He began this page when he decided to open his own business selling percussion equipment, an enterprise that required a strong social media presence. Andy also described that he utilizes his professional Instagram page to "spark interest that could lead to a sale and for people to just appreciate the stuff like a museum." In other words, Andy highlights that Figure 6 illustrates part of a personally meaningful digital archive that Andy uses both to sell products and to enhance visitors' appreciation of percussion equipment.
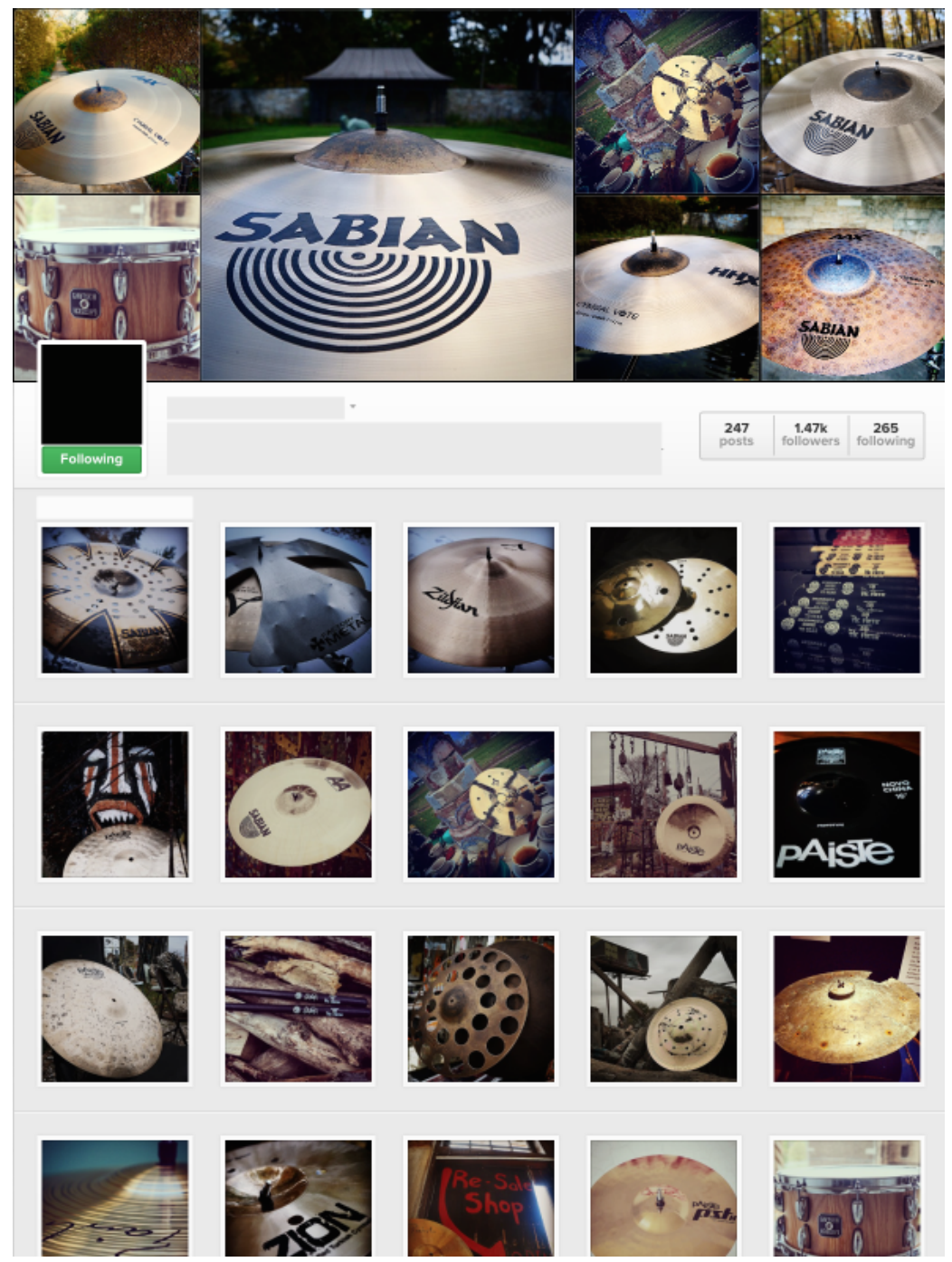

Fig. 6. Andy's professional Instagram page. 
4.3.4 Situating Personal Curation as a Socio-Technical Practice. Following is a sequentially organized progression of posts (i.e., captions and hashtags) from Andy, starting from when Andy began posting on his professional Instagram page. We have replaced names of percussion equipment in captions and hashtags with references to guitar equipment to preserve Andy's anonymity while maintaining a focus on the progression of his posts. Moreover, accompanying each post are photographs that are not shown here, but reflect a progression in photographic techniques (e.g., framing percussion equipment, lighting).

Originally, Andy started by simply posting hashtags, which quickly evolved to include description and price:

\section{\#fender \#vox \#reverb \#5" \#bright finish \#fast \#proto \#guitar old}

Check out this discontinued \#fender \#alpha \#japan \#crash \#thick 15" \#effects they are on blowout prices for \$275 on our \#ebay site \#happyfriday \#keepplaying \#guitars \#gibson guitar \#percussion \#guitarhead \#rockandroll \#strings \#guitarlife \#gear \#design \#japanmade \#fenderguitars

He then progressed to asking questions and relating these questions to special deals:

Anyone looking for the Fender hyper Beta guitars? We have a few left on special, [website link] \#fender \#guitars \#fenderguitars \#strings \#guitars \#tightknot \#design \#city \#mahogany \#veryrare

After nearly a year and a half, Andy often weaved photographs alongside questions, descriptions, complex deals, links to emails and other social media pages:

Anyone remember the original vibroverb effects guitars? They made vintage guitars and custom pickguards before they were in style like nowadays. We have a few rare ones, but here's the deal, I'll send you a free Gibson pickguard with any original vibroverb effects guitar bought on our website, Fender, Gibson, G\&L or even Taylor guitars. Send us an email. \#Factorywood \#Fender \#gibson \#gandl \#taylorguitars \#guitareffects \#guitars

Near the time of his visit, Andy began to write posts that were not focused on deals but, instead, attempted to elicit interaction and feedback from his social network:

What you're thoughts on the Fender Custom Made Pick's? Come on guys, let's hear what you are thinking! \#Fender \#guitars \#guitarmade \#strings \#guitars \#guitargear

The progression illustrates an emerging socio-technical practice in which Andy is refining his ability to: a) collect information from his everyday life through personal information devices; b) edit this information by using photographs, captions, and hashtags to highlight, describe, and orient his followers/social network to specific features of edited information; and c) share this information to develop a personally meaningful digital archive that advances his professional goals, but also serves as a museum for others to learn about and appreciate percussion equipment. 


\section{DISCUSSION \& CONTRIBUTIONS}

We began our analysis by providing an overview of how visitors in our study used personal information devices and social media to collect, edit, and share information from their museum visit. We illustrated how, at certain timescales, people did so to perform identity and manage social relationships while, at other timescales, people did so to develop or contribute to their own personal digital archives. Subsequently, we used methods of interaction geography to situate this analysis with more detailed descriptions of how visitors used personal information devices and social media to collect, edit, and share digital content across different gallery spaces. Finally, we used methods of interaction geography to help identify a case (Andy), which we used to more specifically characterize visitors' use of personal curation; a socio-technical practice in which people collect, edit, share information as they move through physical environments rich with meaning potential in ways that can be used to develop personal digital archives.

Altogether, our analysis advances a definition of curation that is rooted in people's interaction as they move through physical environments such as museums but also considers how these interactions are extended to and shaped by people's social media ecologies and practices. Put differently, personal curation integrates work that studies people's social and cooperative interaction with work in the curating perspective, in this paper, to understand and potentially design for how people collect, edit, and share archival material from museum galleries both during and after visits. We highlight three particular contributions of this work.

Contribution 1. Our analysis illustrates how to combine a spatial focus on people's movement and interaction through the physical environment with an analysis of social media use in order to gain a deeper understanding of practices such as personal curation. In particular, methods of interaction geography provide a way to see and study how people use personal information devices and social media in a manner that links fine grained analyses of people's interaction with larger scale analyses of social media. For example, in this paper, we used these methods to describe how social media practices influence visitors' trajectories of movement and patterns of interaction at exhibits and across gallery spaces. Likewise, we also used these methods to identify and study how dimensions of curation (e.g., collecting, editing, sharing) can occur not only in online settings as is typically the focus of the curating perspective, but also during in the moment interactions of a museum visit.

Contribution 2. Our analysis extends existing research to show in greater detail how people use and link digital information with physical information to shape others' understanding of cultural heritage. Our analysis illustrates the variability of ways that visitors in this study used personal curation to shape others' understandings of cultural heritage based on their own personal interests and professional, cultural, or familial identities. Mika and Olivia, Helen, Marion, and Andy each illustrate different examples of how visitors used personal curation to repurpose different types of cultural heritage content (e.g., song lyrics, construction details of instruments) to shape others' interpretation of that content in different types of settings (e.g., schools, professional social media networks, crafting groups). These examples provide a starting point to begin to describe a variety of ways that visitors to settings such as museums and cultural heritage sites may potentially use personal curation to shape others' understandings of cultural heritage. 
Contribution 3. Museums and other cultural heritages sites widely acknowledge how "the model of the visitor that we posit as the consumer of our products will radically affect how we are enabled to think about how exhibitions should be made" [7]. Our work draws from and extends existing research to inform new visitor models that expand an understanding of visitors solely as passive consumers of intended design. In particular, we suggest personal curation illustrates how some visitors to museums and cultural heritage sites are increasingly curators in large part due to advances in the design and use of personal information devices and social media. A model of visitors as curators provides new insights/opportunities for museums and cultural heritage sites to support visitors' participation with archival collections in ways that are relevant and interconnected to issues in their everyday lives and communities [2 also see 52]. Particularly, such a model extends emerging design efforts in museums and cultural heritage sites that explicitly leverage location-based technologies and social media to support the co-curation of exhibits and interactive installations [7,13]. Likewise, we suggest such a model may also inform a new design space that leverages visitors' personal curation to bridge or index archival media in museums and cultural heritage sites onto the city neighborhoods these media are about, for example, to allow visitors to make and take walking scale city tours that capture under or untold aspects of a city's public history.

\section{LIMITATIONS \& NEXT STEPS}

Making personal curation visible to the museum in this study had a significant impact on this museum. Namely, the museum developed new social media policies (e.g., hashtag/indexing mechanisms) that encouraged the use of personal curation to learn and teach others about museum content in ways that also advanced the museums' marketing and educational goals. More recently, this museum has begun to explore more personalized ways to support visitors' personal curation, for example, by supporting teachers to use museum content to develop their online teaching profiles.

However, we conclude this paper by emphasizing that this is early work with a variety of limitations. We describe four primary limitations here. First, this work draws from one, small exploratory study. Through the information and examples presented in this paper we hoped to provide a broad definition of personal curation and show the extent and variability of personal curation that may be occurring in one particular museum. With the widespread use of personal information devices by visitors to museums and cultural heritage sites, we suggest visitors to these sites may increasingly leverage personal curation. However, future research is necessary to advance such a claim. Likewise, future research and in particular, comparative research across different museums and cultural heritage sites, is needed to more specifically characterize dimensions of personal curation as well as how visitors use personal curation to develop different types of personal digital archives.

Second, methods of interaction geography are only beginning to be expanded to settings beyond the museum described in this paper (e.g., see $[58,59]$ for work that has applied the IGS to visualize and discuss New York City's controversial Stop-And-Frisk Program and to support social studies instruction). Future research will need to explore a variety of questions concerning how to generalize methods described in this paper particularly in collaboration with professional practitioners who are in the best position to read and interpret complex visualizations produced by interaction geography. 
Third, there are inherent limitations to leveraging personal curation to support new or existing designs in museums and cultural heritage sites. In particular, personal curation depends on the quality and density of contextual information (meta-data) available or displayed within these settings, the degree to which copyright holders are willing to allow fair use by members of the public, and the digital mobilities of visitors.

Finally, there are significant ethical considerations to this work. This study was made possible by many generous visitors who volunteered their time to participate in this research. Concepts and methods in this paper necessitate maintaining ethical guidelines and potentially developing new ethical guidelines (e.g., to address issues of informed consent, fair use of media in public or private spaces, intellectual property) [see 9,23]. These issues are beyond the scope of this article but remain a serious concern.

\section{ACKNOWLEDGEMENTS}

This research was made possible by wonderful collaborations with our museum partners, many generous families and visitors participating in this research, and the National Science Foundation (\#1623690). We would also like to thank Leona Schauble, Jennifer Kahn, and CSCW reviewers who provided important suggestions and feedback on early drafts of this paper as well as members of the Space, Learning \& Mobility Lab at Vanderbilt University.

\section{REFERENCES}

[1] S. Allen. 2002. Looking for learning in visitor talk: A methodological exploration. In Learning Conversations in Museums, G Leinhardt, K. Crowley and K. Knutson (Eds.), Learning conversations in museums, 259-303.

[2] L. B. Allen and K. Crowley. 2017. Moving beyond scientific knowledge: Leveraging participation, relevance, and interconnectedness for climate education. International fournal of Global Warming, $12(3$ \& 4), 299-312.

[3] S. Bayne, J. Ross, and Z. Williamson. 2009. Objects, subjects, bits and bytes: learning from the digital collections of the National Museums. Museum and Society 7(2), 110-124.

[4] S. Bitgood. 2000. The role of attention in designing effective interpretive labels. fournal of Interpretation Research, 5(2), 31-45.

[5] S. Bitgood. 2006. An analysis of visitor circulation: movement patterns and the general value principle. Curator: The Museum fournal, 49(4), 463-475.

[6] Magdalena Blöckner, Svetlana Danti, Jennifer Forrai, Gregor Broll, and Alexander De Luca. 2009. Please touch the exhibits!: using NFC-based interaction for exploring a museum. In Proceedings of the 11th International Conference on Human-Computer Interaction with Mobile Devices and Services (MobileHCI '09). ACM, New York, NY, USA.

[7] T. Boon. 2011. Co-Curation and the Public History of Science and Technology. Curator: The Museum fournal, 54(4), 383-387.

[8] D. Boyd, and N. Ellison. 2007. Social Network Sites: Definition, History, and Scholarship. Journal of Computer-Mediated Communication. 13(1): 210-230.

[9] A. S. Bruckman, C. Fiesler, J. Hancock, and C. Munteanu. 2017. CSCW Research Ethics Town Hall: Working Towards Community Norms. In Companion of the 2017 ACM Conference on Computer Supported Cooperative Work and Social Computing (CSCW '17 Companion). ACM, New York, NY, USA, 113-115.

[10] S. Chang, V. Kumar, E. Gilbert, and L. G. Terveen. 2014. Specialization, homophily, and gender in a social curation site: findings from pinterest. In Proceedings of the 17th ACM Conference on Computer-Supported Cooperative Work and Social Computing. ACM, $674-686$.

[11] K. Charmaz. 2006. Constructing grounded theory: A practical guide through qualitative analysis. Thousand Oaks, CA: Sage.

[12] D. Christidou. Art on the move: The role of joint attention in visitors' encounters with artworks. 2018. Fournal of Learning, Culture and Social Interaction.

[13] L. Ciolfi. 2013. The collaborative work of heritage : open challenges for CSCW. In: Bertelson, Olav W., Ciolfi, Luigina, GRASSO, Maria Antonietta and Papadopoulos, George Angelos, (Eds.), ECSCW 2013: Proceedings of the 13 ${ }^{\text {th }}$ European Conference on Computer Supported Cooperative Work. London, Springer, 83-101.

[14] K. Crowley and M. Jacobs. 2002. Building islands of expertise in everyday family activity. In G. Leinhardt, K. Crowley, and K. Knutson (Eds.), Learning conversations in museums (pp. 333-356). Mahwah: Lawrence Erlbaum Associates.

[15] E. Dawson and E. Jensen. 2011. Towards a contextual turn in visitor studies: evaluating visitor segmentation and identity-related motivations. Visitor Studies, 14, 127-140.

[16] M. A. DeVito, J. Birnholtz, and J. T. Hancock. 2017. Platforms, People, and Perception: Using Affordances to Understand SelfPresentation on Social Media. In Proceedings of the 2017 ACM Conference on Computer Supported Cooperative Work and Social Computing (CSCW '17). ACM, New York, NY, USA, 740-754.

[17] K.M. Ellenbogen, J.J. Luke, and L.D. Dierking. 2004. Family learning research in museums: An emerging disciplinary matrix? Science Education, 88(S1), S48-S58.

[18] N. B. Ellison and D. Boyd. 2013. Sociality through Social Network Sites. In Dutton, W. H. (Ed.), The Oxford Handbook of Internet

Proceedings of the ACM on Human-Computer Interaction, Vol. 2, No. CSCW, Article 158, Publication date: November 2018. 
Studies. Oxford: Oxford University Press, 151-172.

[19] N. B. Ellison, C. Steinfield, and C. Lampe. 2011. Connection strategies: Social capital implications of Facebook-enabled communication practices. New Media and Society, 13(6), 873-892.

[20] N. B. Ellison, R. Heino, and J. Gibbs. 2006. Managing impressions online: Self-presentation processes in the online dating environment. fournal of Computer-Mediated Communication, 11, 415-441.

[21] M. Eslami et al. 2015. "I Always Assumed That I Wasn't Really That Close to [Her]": Reasoning About Invisible Algorithms in News Feeds. In Proceedings of the $33^{\text {rd }}$ Annual ACM Conference on Human Factors in Computing Systems (CHI '15). ACM, 153-162.

[22] J.H. Falk and L.D. Dierking. 1992. The Museum Experience, Whalesback Books, Washington.

[23] C. Fiesler, A. Young, T. Peyton, A. S. Bruckman, Mary Gray, Jeff Hancock, and Wayne Lutters. 2015. Ethics for Studying Online Sociotechnical Systems in a Big Data World. In Proceedings of the 18th ACM Conference Companion on Computer Supported Cooperative Work and Social Computing (CSCW'15 Companion). ACM, New York, NY, USA, 289-292.

[24] A. Fletcher and M. J. Lee. 2012. Current social media uses and evaluations in American museums. Museum Management and Curatorship, 27(5), 505-521.

[25] L. Fosh, S. Benford, and B. Koleva. 2016. Supporting Group Coherence in a Museum Visit. In Proceedings of the 19th ACM Conference on Computer-Supported Cooperative Work \& Social Computing (CSCW '16). ACM, New York, NY, USA, 1-12.

[26] H. Fuks et al. 2012. Collaborative museums: an approach to co-design. In Proceedings of the ACM 2012 conference on Computer Supported Cooperative Work (CSCW '12). ACM, New York, NY, USA, 681-684.

[27] E. Giaccardi. 2012. Heritage and social media: Understanding heritage in a participatory culture, Routledge.

[28] B.G. Glaser and A.L. Strauss. 1967. The discovery of grounded theory: Strategies for qualitative research. Chicago, IL: Aldine.

[29] K.D. Good. 2013. From scrapbook to Facebook: A history of personal media assemblage and archives. New Media and Society, 15(4), 557-573.

[30] R. E. Grinter et al. 2002. Revisiting the visit: understanding how technology can shape the museum visit, In Proceedings of the ACM 2002 conference on Computer Supported Cooperative Work (CSCW '02). ACM, New York, 146-155.

[31] T. Hagerstrand. 1970. What about people in regional science? Papers in regional science, 24(1), 7-24.

[32] R. Hall, and R. Stevens. 2015. Interaction analysis approaches to knowledge in use. Knowledge and Interaction: A Synthetic Agenda for the Learning Sciences, 72-108.

[33] C. Heath and D. vom Lehn. 2008. Configuring 'Interactivity' enhancing engagement in science centres and museums. Social Studies of Science, 38(1), 63-91.

[34] B. Hogan. 2010. The presentation of self in the age of social media: distinguishing performances and exhibitions online. Bulletin of Science, Technology and Society, 30, 377-386.

[35] Y. L. Huang, K. Starbird, M. Orand, S. A. Stanek, and H. T. Pedersen. 2015. Connected Through Crisis: Emotional Proximity and the Spread of Misinformation Online. In Proceedings of the 18th ACM Conference on Computer Supported Cooperative Work and Social Computing (CSCW '15). ACM, New York, NY, USA, 969-980.

[36] M. Ito et al. 2013. Connected learning: An agenda for research and design. Digital Media and Learning Research Hub.

[37] B. Jordan and A. Henderson. 1995. Interaction analysis: Foundations and practice. The journal of the learning sciences, 4(1), 39-103.

[38] D. Merritt, J. Jones, M. S. Ackerman, and W. S. Lasecki. 2017. Kurator: Using The Crowd to Help Families With Personal Curation Tasks. In Proceedings of the 2017 ACM Conference on Computer Supported Cooperative Work and Social Computing (CSCW '17). ACM, New York, NY, USA, 1835-1849.

[39] J. Lanir, T. Kuflik, J. Sheidin, N. Yavin, K. Leiderman, and M. Segal. 2017. Visualizing museum visitors' behavior: Where do they go and what do they do there? Personal Ubiquitous Computing, 21(2), 313-326.

[40] J. Lave, M. Murtaugh, and O. de la Rocha. 1984. The dialectics of arithmetic in grocery shopping. In B. Rogoff and J. Lave (Eds.), Everyday cognition: Its development in social context (pp. 67-94). Cambridge: Cambridge University Press.

[41] S. Lindley, C. C. Marshall, R. Banks, A. Sellen, and T. Regan. 2013. Rethinking the web as a personal archive. In Proceedings of the 22nd international conference on World Wide Web (WWW '13). ACM, New York, NY, USA, 749-760.

[42] J. Kaye et al. 2006. To have and to hold: exploring the personal archive. In Proceedings of the SIGCHI Conference on Human Factors in Computing Systems (CHI '06), 275-284.

[43] S.B. Liu. 2010. Trends in Distributed Curatorial Technology to Manage Data Deluge in a Networked World. The European fournal for the Informatics Professional, $\mathrm{XI}(4)$

[44] C. Marshall, R. McCown, and M.L., Nelson. 2007. Evaluating personal archiving strategies for internet-based information. In Proc. Archiving, 151- 56

[45] A. E. Marwick and D. Boyd. 2010. I tweet honestly, I tweet passionately: Twitter users, context collapse, and the imagined audience. New Media and Society, 13(1), 114-133.

[46] W. Odom, A. Sellen, R. Harper and E. Thereska. Lost in translation: Understanding the possession of digital things in the cloud. In Proceedings of the SIGCHI Conference on Human Factors in Computing Systems (CHI '12), 781-790.

[47] K. O'Hara, T. Kindberg, M. Glancy, L. Baptista, B. Sukumaran, G. Kahana, and J. Rowbotham. 2007. Social practices in location-based collecting. In Proceedings of the SIGCHI Conference on Human Factors in Computing Systems (CHI '07). ACM, New York, NY, USA, 1225-1234.

[48] R. Parry (Ed.). 2010. Museums in a Digital Age. New York, NY, Routledge.

[49] E. Rader and R. Gray. 2015. Understanding User Beliefs About Algorithmic Curation in the Facebook News Feed. In Proceedings of the 33rd Annual ACM Conference on Human Factors in Computing Systems (CHI '15). ACM, 173-182.

[50] S. Reeves and B. Brown. 2016. Embeddedness and sequentiality in social media. In Proceedings of the 19th ACM Conference on Computer-Supported Cooperative Work and Social Computing (CSCW '16). ACM, New York, NY, USA, 1052-1064.

[51] J. Roberts and L. Lyons. 2017. The value of learning talk: applying a novel dialogue scoring method to inform interaction design in an open-ended, embodied museum exhibit. International fournal of Computer-Supported Collaborative Learning, 12(4), 343-376.

[52] S. M. Rowe, J. V. Wertsch, and T. Y. Kosyaeva. 2002. Linking Little Narratives to Big Ones: Narrative and Public Memory in History

Proceedings of the ACM on Human-Computer Interaction, Vol. 2, No. CSCW, Article 158, Publication date: November 2018. 
Museums. Culture and Psychology, 8(1), 96-112.

[53] L. Schauble, G. Leinhardt, and Laura Martin. 1997. A framework for organizing a cumulative research agenda in informal learning contexts. Journal of Museum Education, 22, 3-7.

[54] R. Schwartz and G. R. Halegoua. 2014. The spatial self: Location-based identity performance on social media. New Media and Society, 17(10), 1643-1660.

[55] B. Serrell. 1994. The Question of Visitor Styles. In: S. Bitgood (Ed.). Visitor Studies: Theory, Research, and Practice, 6(1), 48-53. Jacksonville AL.

[56] B.R. Shapiro, R. Hall, and D. Owens. 2017. Developing and Using Interaction Geography in a Museum. International fournal of Computer-Supported Collaborative Learning, 12(4), 377-399.

[57] B.R. Shapiro and R. Hall. 2017. Making Engagement Visible: The Use of Mondrian Transcripts in a Museum. In Proceedings of the 12th International Conference for Computer Supported Collaborative Learning, (Vol. 1, pp. 33-40). Philadelphia, PA: International Society of the Learning Sciences.

[58] B.R. Shapiro and Francis A. Pearman II. 2017. Using the Interaction Geography Slicer to Visualize New York City Stop and Frisk. In Proceedings of the IEEE VIS 2017 Arts Program, VISAP'17. Phoenix, AZ.

[59] B.R. Shapiro. 2017. Using Space Time Visualization in Learning Environment Design. In Proceedings of the 2017 CHI Conference Extended Abstracts on Human Factors in Computing Systems (CHI EA '17). ACM, Denver, CO, USA. 178-183.

[60] L. F. Smith, J. K. Smith, P. P. L. Tinio. 2017. Time spent viewing art and reading labels. Psychology of Aesthetics, Creativity, and the Arts, 11(1), 77-85.

[61] R. Steier. 2014. Posing the question: Visitor posing as embodied interpretation in an art museum. Mind, Culture, and Activity, 21(2), $148-170$.

[62] P. Tolmie, S. Benford, C. Greenhalgh, T. Rodden, and S. Reeves. 2014. Supporting group interactions in museum visiting. In Proceedings of the 17th ACM conference on Computer supported cooperative work and social computing. ACM, New York, NY, USA, 1049-1059.

[63] K. Tzortzi. 2014. Movement in museums: mediating between museum intent and visitor experience. Museum Management and Curatorship, 29(4), 327-348.

[64] N.A. Van House. 2011. Personal photography, digital technologies and the uses of the visual. Visual Studies, 26(2), 125-134.

[65] D. vom Lehn, C. Heath, and J. Hindmarsh. 2002. Exhibiting Interaction: Conduct and Collaboration in Museums and Galleries. Symbolic Interaction, 24(2), 189-216.

[66] Y. Wang, M. Niiya, G. Mark, S. Reich, and M. Warschauer. 2015. Coming of age (digitally): An ecological view of social media use among college students. In Proceedings of the 18th ACM conference on Computer supported cooperative work and social computing. ACM, New York, NY, USA, 571-582.

[67] R. D. Watkins, A. Sellen, and S. E. Lindley. 2015. Digital collections and digital collecting practices. In Proceedings of the 33rd Annual ACM Conference on Human Factors in Computing Systems (CHI '15), 3423-3432.

[68] R. Wilken. 2015. Mobile media and ecologies of location. Communication Research and Practice, 1, 42-57.

[69] S. S. Yalowitz, K. Bronnenkant. 2009. Timing and tracking: unlocking visitor behavior. Visitor Studies, 12, 47-64.

[70] X. Zhao and S. Lindley. 2014. Curation through use: Understanding the personal value of social media. In Proceedings of the SIGCHI Conference on Human Factors in Computing Systems (CHI '14). ACM, New York, NY, USA, 2431-2440.

[71] X. Zhao, N. Salehi, S. Naranjit, S. Alwaalan, S. Voida, and D. Cosley. 2013. The many faces of Facebook: Experiencing social media as performance, exhibition, and personal archive. In Proceedings of the SIGCHI Conference on Human Factors in Computing Systems (CHI '13). ACM, New York, NY, USA, 1-10.

Received April 2018; revised July 2018; accepted September 2018.

Proceedings of the ACM on Human-Computer Interaction, Vol. 2, No. CSCW, Article 158, Publication date: November 2018. 